\title{
POLÍTICAS REGIONAIS E O DESAFIO DE DIALOGAR COM A DIVERSIDADE REGIONAL BRASILEIRA: O CASO DO RIO GRANDE DO SUL
}

\author{
Victor da Silva Oliveira \\ Universidade Federal do Sul e Sudeste do Pará \\ Instituto de Estudos do Trópico Úmido, Xinguara, PA, Brasil \\ victorsoliveira@unifesspa.edu.br \\ Tania Bacelar de Araújo \\ Universidade Federal de Pernambuco \\ Pós-Graduação em Geografia, Recife, PE, Brasil \\ taniabacelar@ceplanconsult.com.br
}

\begin{abstract}
RESUMO
O processo de formação socioeconômica do Brasil resultou na consolidação do lastro de desigualdades regionais encontradas na atualidade. $\mathrm{Em}$ determinados períodos, pontualmente, algumas regiões foram alvo de qualificação técnica para o atendimento de politicas governamentais. Não obstante, no interior dos entes federados situações semelhantes ocorrem. No Rio Grande do Sul, encontra-se na atualidade considerável diversidade e desigualdade, com carências historicamente não atendidas. Na tentativa de sanar esses desequilíbrios e assumir a diversidade como uma oportunidade para o desenvolvimento, políticas públicas recentes foram executadas, como o Programa Territórios da Cidadania - em escala federal - e dos Conselhos Regionais de Desenvolvimento do Rio Grande do Sul - estadual. A pesquisa que fundamenta o presente artigo buscou analisar o tratamento das peculiaridades regionais em ambas as políticas. Os resultados apontaram a inserção das peculiaridades nas políticas, especialmente advindas de demandas identificadas nos processos de participação social. No entanto, há presença significativa de demandas básicas, corriqueiras na maioria das regiões interioranas.
\end{abstract}

Palavras-chave: Desenvolvimento regional. Geografia regional. Participação social. Políticas públicas. Política regional.

\section{REGIONAL POLICIES AND THE CHALLENGE TO DIALOGUE WITH BRAZILIAN REGIONAL DIVERSITY: THE CASE OF RIO GRANDE DO SUL}

\begin{abstract}
The process of socioeconomic formation in Brazil resulted in the consolidation of the ballast of regional inequalities found today. In certain periods, occasionally, some regions were subject to technical qualification to meet government policies. Nevertheless, within the federated entities similar situations occur. In Rio Grande do Sul, it is found in considerable diversity and inequality today, with historically unmet needs. In an attempt to remedy these imbalances and take diversity as an opportunity for development, recent public policies have been implemented, such as the Citizenship Territories Program - at federal level - and the Regional Development Councils of Rio Grande do Sul - state. The research that underlies this article sought to analyze the treatment of regional peculiarities in both policies. The results showed the inclusion of peculiarities in policies, especially arising from demands identified in the processes of social participation. However, there is a significant presence of basic demands, common in most interior regions.
\end{abstract}

Keywords: Regional development. Regional geography. Social participation. Public policies. Regional policy. 


\section{INTRODUÇÃO}

No decorrer da formação socioeconômica do Brasil, transformações internas e externas de diversas ordens teceram 0 atual cenário de desigualdades sociais e regionais. Em grande parte da sua história, com vinculações comerciais majoritariamente voltadas para o exterior e em relativamente curtos períodos orientados para o mercado interno, as nuanças políticas, econômicas e produtivas que geraram um passivo de desigualdade e concentração privilegiam determinados estratos sociais, setores e regiões em detrimento de outros.

A estrutura social hierárquica herdada do período escravocrata e a condição de colônia que delineou os esforços produtivos para o mercado externo teceram condições primordiais - mesmo que não únicas - para a construção histórica do país, gerando as bases da exclusão e elegendo porções territoriais privilegiadas. Como integrante da realidade brasileira, o estado do Rio Grande do Sul guarda similaridades com o ocorrido no país, especialmente no referente às desigualdades regionais e estratificação social.

Fatos esses que suscitaram em passado distante e próximo tentativas de desagregação de porções do território. Justamente com objetivo de diminuir lacunas regionais e sociais, diversas ações relativamente recentes foram implementadas. Entre estas, destacam-se duas. Os Conselhos Regionais de Desenvolvimento (COREDEs) do Rio Grande do Sul que buscam discutir e atuar para diminuição das desigualdades regionais baseados em iniciativas associadas com a sociedade regional e valorização das peculiaridades de cada região e ampliação dos canais de participação social.

Na escala federal, o Programa Territórios da Cidadania (PTC) oriundo do amadurecimento de ações vinculadas ao antigo Ministério do Desenvolvimento Agrário (MDA), propôs uma alternativa às práticas setoriais rígidas e tornou o território como ponto inicial e final de uma atuação que buscou compreendê-lo de forma ampliada e considerando as forças locais de poder na configuração da política que visou estruturar e aumentar a oferta de bens sociais a territórios marginalizados da pauta política.

Ambas as propostas, mesmo que com viés distinto, enfrentam o passivo histórico que posicionou as desigualdades regionais encontradas no Brasil em níveis elevados. Atuando em uma escala distinta da tríade afirmada no pacto federativo e de forma intersetorial, diversas são as resistências encontradas por essas políticas que somam atributos de ações regionais realizadas em anos anteriores e do momento político de sua formulação na tratativa de buscar o desenvolvimento, tendo as peculiaridades regionais como vetor de potencialização para o desenvolvimento, como trata Araújo (2000).

Diante dessas duas propostas foi buscado aqui analisar o tratamento das peculiaridades regionais do Rio Grande do Sul nos Planejamentos Estratégicos Regionais (2009/2010) realizados pelos COREDEs e no Programa Territórios da Cidadania, buscando especialmente identificar os determinantes de maior ou menor aderência às especificidades regionais em ambas as políticas.

A hipótese de partida aborda o fato de no Brasil, em geral, as políticas públicas, mesmo as de caráter territorial, tenderem a desconsiderar as diversidades das regiões para as quais se dirigem. Esse fato decorre da prevalência da abordagem setorial e pelo processo de formulação das políticas por iniciativas top-down que tendem a não considerar a rica diversidade regional do país e abordam as regiões com formulações únicas. Entre os fatores que contribuem para a aderência maior ou menor às peculiaridades regionais nas políticas públicas, dois tendem a se destacar: a) a forma de construção da política; e b) o processo de participação social.

Para apresentação dessa análise, o presente artigo está estruturado em cinco partes, além desta introdução. Na seção seguinte é discutido o marco histórico-conceitual a partir da consolidação das desigualdades e das peculiaridades regionais do Brasil e do Rio Grande do Sul. Posteriormente são apresentados os pressupostos principais de ambas as políticas em tela neste estudo. Na quarta seção são abordados os procedimentos metodológicos que nortearam a pesquisa. Após, é analisada a síntese dos resultados encontrados a partir da aplicação da metodologia proposta. Por fim, são tecidos comentários em caráter de considerações finais.

\begin{tabular}{|c|c|}
\hline Geografia & Uberlândia-MG \\
\hline
\end{tabular}




\section{DESIGUALDADES E PECULIARIDADES REGIONAIS DO BRASIL E DO RIO GRANDE DO SUL}

A preocupação em atuar para mitigar os efeitos das desigualdades entre regiões surge, antes de tudo, pela existência de um conjunto de desequilíbrios que perpassam por aspectos econômicos e políticos. Entre países, é muito diverso o grau de desigualdade regional. No Brasil, o percurso histórico de formação socioeconômica possibilita perceber pistas que evidenciam as razões para esse fato que inicia com o aproveitamento econômico da diversidade do país e passa a gerar um passivo de desigualdade.

Como ponto inicial, pode-se assumir a consolidação da sociedade agrária no Brasil que, desde o descobrimento em 1500 até a transição para a sociedade urbano-industrial, em 1930 segundo Pochmann (2010), operou como principal e quase exclusiva força interna no delineamento da produção nacional. Por mais de quatro séculos o padrão agrário exportador reinou na pauta econômica da política nacional, gerando extremas segregações sociais e desigualdades regionais entre os poucos núcleos produtores geridos por elites com fortes vínculos externos.

Desde os primeiros ciclos econômicos agrários foram gestadas características no cenário econômico e territorial do país que se perpetuaram. Em linhas gerais a organização da estrutura socioeconômica do país voltadas para a dinâmica externa congrega como principais características: produção em monocultura realizada em grandes propriedades, com altos índices de concentração de terra e produção para exportação, força de trabalho escravo que posteriormente se assalariou por baixos salários, desmobilizando a possibilidade criação de mercado interno.

O ambiente econômico internacional de crise ao final da década de 1920 internamente solapou a capacidade de importação a qual era auferida a partir da exportação do café que teve seu preço reduzido de forma drástica no cenário mundial. Segundo Tavares (1977), é iniciado, ali, um processo de transformação de uma economia antes voltada "para fora" para outra organizada "para dentro", a partir do processo de industrialização via substituição de importações. Regionalmente esse processo ocorrera principalmente nas áreas cultivadoras de café. Ao acumular capital, o complexo cafeeiro gerou condições de transforma-lo em capital industrial e criou as condições para as mudanças necessárias.

A escala de ação privilegiada no período de intensificação da industrialização foi a nacional. As relações de poder oriundas das políticas estratégicas, as regulamentações e os embates de classes tinham como arena a economia e o sistema político do território nacional. Os lugares/regiões possuindo papel secundário acabaram por não ser contemplados em totalidade. Prevaleceram os interesses de poucos lugares.

A prevalência da escala nacional nas definições econômicas e políticas do Brasil se estendem até meados da década de 1970 quando a crise internacional do petróleo e da produção fordista se instala e acarretam diversas repercussões nas economias nacionais, como a modificação do papel do Estado-Nação e abertura de caminho para a financeirização com a eleição de outras escalas de ação em países como o Brasil.

O Estado não desapareceu, porém seu papel intervencionista foi substituído pelo fomento na atração de investimentos e facilitação das exportações, preparando as regiões selecionadas para o recebimento de grandes empresas. Estas passaram a agir diretamente no território, aumentando seu poder político e diminuindo o poder do Estado, privilegiando no período, de acordo com Araújo (2007), as escalas global e local em detrimento do nacional.

A substituição do projeto nacional de desenvolvimento em troca do favorecimento de determinadas regiões para aporte da grande empresa, as 'regiões ganhadoras', como afirma Cargnin (2011). Interliga-se diretamente a escala global e local/regional, gerando práticas políticas corriqueiras no cenário brasileiro, como as guerras fiscais e o sucateamento e descrédito do planejamento em longo prazo e para macrorregiões.

Entre a ascensão da flexibilização da produção e as transformações mais recentes postas pela globalização que puseram em evidencia a escala global e valorizaram peculiaridades do local, está a regulação do Estado-nação como uma necessidade. Entende-se que em um país com a diversidade natural e cultural e a histórica desigualdade social e regional construída como no caso brasileiro, as ações propositivas do Estado tem relevância que não podem ser endereçadas a outras escalas e tampouco dirigidas ao mercado. 
Nos primeiros anos do século XXI, políticas territoriais e regionais regidas pelo governo federal, intercalando distintas escalas e, sobretudo, refortalecendo o Estado nacional são retomadas, conforme Pochmann (2010). Foi buscado trazer novamente para o Estado a responsabilidade de propor intervenções de cunho territorial no âmbito nacional, buscando articular a necessidade de combater as estruturais desigualdades regionais e sociais do país com a valorização da rica diversidade regional brasileira.

A reorganização dos investimentos públicos poderia trazer para pauta política estratos sociais marginalizados historicamente, compatibilizando a agenda macroeconômica nacional com ações de emancipação social, inclusive com vinculação por lei de recursos a serem destinados a política social. Deste redirecionamento político, propostas diferenciadas no âmbito nacional e em alguns estados surgem, reunindo esforços para viabilizar projetos territoriais de desenvolvimento para além dos tradicionais cortes setoriais, na busca por valorizar a diversidade e buscar diminuir desigualdades sociais e regionais herdadas.

Estruturada a compreensão da origem e persistência dos desequilíbrios regionais do Brasil, cabe descer à escala estadual para cunhar as peculiaridades do Rio Grande do Sul no que tange a sua heterogeneidade regional, objetivo de análise nas duas políticas públicas investigadas e compõe o eixo central das hipóteses aqui trazidas.

O processo de configuração da sociedade gaúcha originou importante dualidade resultante dos primeiros ciclos de ocupação. Diversos foram os momentos de incentivo do governo para a fixação de população no território gaúcho, primeiramente em grandes propriedades rurais e, após, em minifúndios produtores de alimentos agrícolas.

Costumeiramente, o território gaúcho é dividido em três grandes regiões - Sul, Norte e Nordeste, conforme figura 01 - para compreensão das suas diferenças, proposta trazida por Alonso e Bandeira (1994). No nordeste situa-se o eixo Porto Alegre - Caxias do Sul, local de início do assentamento europeu no estado - século XIX. Atualmente é a área de maior dinamismo econômico, com consideráveis taxas de industrialização, elevada taxa de participação da produção econômica estadual e indicadores de desenvolvimento humano entre os maiores do Brasil.

Figura 01 - Macrorregiões do Rio Grande do Sul.

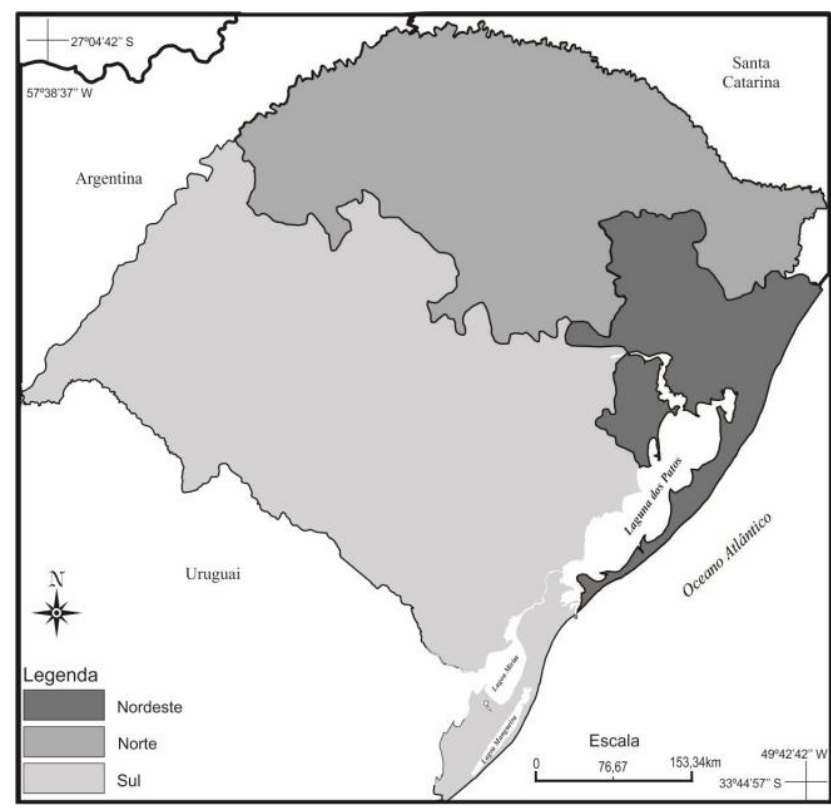

Fonte - Alonso, Bandeira e Benetti (1994), adaptado pelos autores (2017).

Os centros urbanos nessa região desenvolveram-se com alto índice de concentração demográfica, ofertando um mercado consumidor considerável e um grande número de cidades com pequena área territorial, com alguns polos médios e diversificada atividade rural. Formada por uma mão de obra

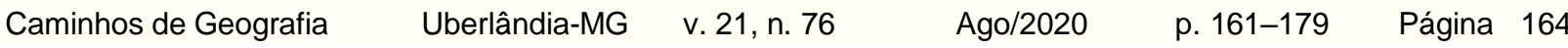


familiar, livre, na região houve desde sua ocupação por europeus acesso à terra e à educação como princípios democráticos básicos, organizando o que Brose (2005) denominou de "uma sociedade mais igualitária".

$\mathrm{Na}$ região sul do estado uma das principais características herdadas do processo de formação territorial, iniciado no século XVIII, foi a concentração na posse da terra. A concessão de extensas sesmarias durante a ocupação do sul do Brasil resultou em uma população rarefeita distribuída em cidades de porte médio com grandes áreas territoriais e em número significativamente menor que no nordeste e norte do Estado. Além disso, a estrutura social altamente hierarquizada herdada do passado escravista impossibilitou o acesso à terra dos menos favorecidos, criando uma centralidade política que dificultou o processo de democratização de serviços básicos na região. O principal centro urbano que escoava a produção das áreas de campos no passado vinculou-se essencialmente com a exportação, sem articulação com atividades de processamento e geração de renda, fato atrelado ao pequeno mercado causado pela densidade demográfica baixa dos grandes latifúndios pecuaristas, não havendo potencialização endógena para a criação de atividade manufatureira sustentável.

O norte do estado foi a última região a ser ocupada por imigrantes europeus, já no final do século XIX e início do XX. Foi destino de fluxos de migrantes oriundos das áreas zonas de povoamento mais antigos de alemães e italianos - principalmente. Com a constante fragmentação das propriedades, sobretudo por razões de sucessão hereditária, a pecuária extensiva deu espaço para a agropecuária realizada em pequenas e médias propriedades. O processamento de produtos alimentícios tornou o setor de industrialização expressivo na região, assim como insumos e implementos agrícolas.

Com intensificação das rupturas regionais do Estado, de acordo com Bandeira (2010) paulatinamente ampliou-se as preocupações com as desigualdades regionais do Rio Grande do Sul. Além das estruturas regionais distintas, por vezes antagônicas, uma gama de condições foi historicamente negada a um conjunto da população, como nas regiões interioranas do país. Um leque de questões 'básicas' permanece como passivo histórico, como saneamento básico, educação de qualidade, infraestrutura, enfim. As políticas aqui analisadas visam, a partir das peculiaridades das regiões, conceber estratégias de desenvolvimento para superar os desequilíbrios herdados.

\section{POLÍTICAS DE ATENÇÃO ÀS DESIGUALDADES REGIONAIS A PARTIR DA VALORIZAÇÃO DA DIVERSIDADE}

A formação socioeconômica do Rio Grande do Sul juntamente com os processos da atualidade formaram no interior da unidade federativa um espaço heterogêneo. Esse movimento fomentou experiências desenvolvidas no Estado, baseado em atividades endógenas articuladas a processos de mobilização social em prol do atendimento de demandas regionais de ordem 'básica' não atendidas por políticas setoriais tradicionais.

A institucionalização de entes públicos, porém não estatais, e o teste de inúmeros procedimentos de participação popular marcaram a trajetória do Estado, como afirma Veiga (2006), na busca por superar as desigualdades territoriais, ações que visam promover o desenvolvimento a partir de bases já estruturadas e com adesão social garantida pela sua participação nos processos de deliberação.

Cabe nesse momento contextualizar e problematizar as duas políticas públicas de corte territorial analisadas: o Programa Territórios da Cidadania e a criação dos Conselhos Regionais de Desenvolvimento.

Os Conselhos tiveram sua institucionalização a partir de Lei em 1994. Entretanto, já haviam ações institucionalizadas sob o nome 'COREDE' desde 1991 e o seu embrião era ainda mais antigo. Possuem origem na própria formação do Estado no RS que, ao contrário da grande maioria das iniciativas de desenvolvimento no Brasil, segundo Brose (2007), foi baseado na mobilização social herdada das experiências associativas e comunitárias das colônias alemãs e italianas.

Não por acaso, iniciativas como dos COREDEs surgiram no interior do Estado, discutidas principalmente em universidades comunitárias, criadas para possibilitar o acesso à educação superior da população não residente nas capitais, postura de democratização ao acesso à educação e outros bens sociais encontrada na região norte do Estado (SCHMIDT, 2010).

As experiências regionalizadas dessas instituições visando o desenvolvimento lograram relativo êxito, principalmente no tocante ao conhecimento acumulado em cada nova gestão do Estado e definição de novos processos. Assim, uma atribuição legal dos Conselhos desde sua instituição legal é a 
produção e discussão de diagnósticos regionais, visando à elaboração de planos estratégicos de desenvolvimento regional.

Diante dessa atribuição, o Fórum dos COREDEs a partir de 2007 assumiu como prioridade para a manutenção e fortalecimento dos Conselhos a revisão dos Planejamentos já realizados e a elaboração de novos para as 28 regiões coredianas. Ocorreu, entre 2009 e 2010, o primeiro esforço conjunto de planificação dos COREDEs, com metodologia única e passível de análise crítica frente aos seus objetivos, sobretudo o de potencializar o desenvolvimento regional do Estado a partir das peculiaridades regionais.

Também com objetivo de intervir de maneira estruturada e com a participação da sociedade, o Programa Territórios da Cidadania (PTC), foi lançado em 2008. Em anos anteriores já havia antecedentes que serviram de base para a sua criação. Echeverri (2010) divide em três etapas o processo de amadurecimento das políticas territoriais até o lançamento do PTC: a) antecedentes que originaram o marco de gestão; b) processo de construção das estratégias; e c) consolidação das estratégias.

Primeiramente, os antecedentes que vieram a trazer para pauta política brasileira o caráter territorial possuem bases em ações do setor rural, especialmente as lutas agrárias e a construção de um ambiente institucional específico. A segunda etapa para exposição do amadurecimento da política territorial no Brasil - que culminou no PTC - parte do processo de construção de uma estratégia de abordagem territorial, com superação do enfoque setorial pelo territorial. Por fim, consolidam-se as estratégias, ao ser alterado o foco de intervenção introduzindo a unidade territorial como alvo da política de desenvolvimento rural e não mais a produção agrícola.

Os planos de atuação nos Territórios, construídos com larga participação dos agentes sociais, tiveram por finalidade oferecer mecanismos de gestão do território e dar uma visão geral das competências presentes no mesmo, para estas serem pleiteadas junto a políticas públicas. A interescalaridade e intersetorização das ações do PTC ficam evidentes com a existência de Colegiados nos três entes federativos. O federal age de forma estruturante, reunindo os ministérios partícipes, selecionando os territórios atingidos pelo programa, organizando as ações federais e a avaliação da política. Participam representantes dos ministérios envolvidos.

Já os Colegiados Estaduais trabalham para a execução das ações nos territórios, subsidiando trabalho dos assessores territoriais, na escala municipal, que são vinculados ao MDA.

No contexto de estruturação e amadurecimento de políticas de corte territorial, que partem da valorização das peculiaridades regionais como vetor de desenvolvimento, coube questionar se em um Estado reconhecidamente heterogêneo está ocorrendo de fato à aderência das peculiaridades nas propostas de ambas as políticas. Esse esforço fora realizado por pesquisa, contemplando os quatro TC definidos no Rio Grade do Sul e onze COREDEs que os sobrepõe - abrangendo 162 municípios dos 496 totais - conforme figura 02 .

Figura 02 - Área de abrangência da pesquisa. 


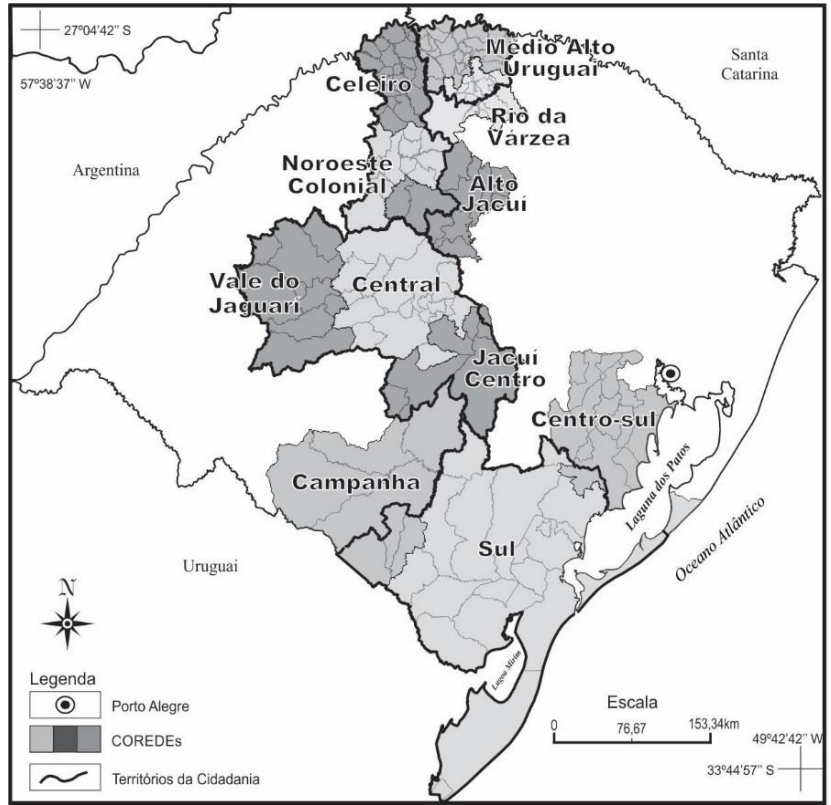

Fonte - SEPLAN/RS e PTC, adaptado pelos autores (2017).

\section{PROPOSTA METODOLÓGICA DE ANÁLISE DE POLÍTICAS REGIONAIS DE ATENÇÃO ÀS PECULIARIDADES REGIONAIS}

Para compreensão das etapas de pesquisa realizadas e apresentação de cada técnica junto ao seu processo construtivo, dividiu-se em quatro grandes etapas de investigação que se subdividiram em diversas atividades, as quais possuem inter-relação entre si. Duas dessas etapas foram brevemente apresentadas anteriormente: a) a explicitação da constituição das peculiaridades regionais do Brasil e do Rio Grande do Sul; e b) apresentação das políticas territoriais, estadual e federal selecionadas. Além dessas, outras duas foram realizadas: c) processo de construção dos planos - metodologia e agentes; e d) a formulação de propostas oriundas das políticas. Apresenta-se ambas na sequência.

Para perceber o processo de construção dos planos territoriais, a terceira etapa da pesquisa, foram evidenciados os elementos estruturantes na construção dos mesmos, buscando assim elementos que determinam ou contribuem para a aderência das peculiaridades regionais nos planos territoriais. Nessa etapa foram realizadas duas atividades. Primeiro a revisão das metodologias norteadoras para construção dos planos de ambas as políticas analisadas a partir de questionamentos que, baseados na Escala Likert, estipularam se todas as etapas propostas foram cumpridas e estão apresentadas nos documentos finais, fazendo uso da transformação da quantidade em qualidade. Os quadros 01 e 02 são exemplos de como foram realizadas estas verificações, tanto para os COREDEs como para o PTC.

Quadro 01 - Exemplo de questões que compõe a matriz avaliativa do planejamento do PTC.

[Especificação do território]

BLOCO 1 - Elementos do diagnóstico técnico/territorial - PTC 


\begin{tabular}{|c|c|c|}
\hline 01 & $\begin{array}{l}\text { Aspectos territoriais do TC: } \\
\text { ( ) resgate da formação territorial } \\
\text { ( ) caracterização geral do território } \\
\text { ( ) identificação das transformações recentes na } \\
\text { região } \\
\text { ( ) outros desta natureza/ especifique }\end{array}$ & $\begin{array}{l}\text { [0] O plano sequer comenta nenhum destes } \\
\text { itens; } \\
\text { [1] O plano comenta, mesmo que em poucos } \\
\text { parágrafos, sobre um dos itens ao lado } \\
\text { (qualquer deles); } \\
\text { [2] O plano comenta, mesmo que em poucos } \\
\text { parágrafos, sobre dois dos itens ao lado } \\
\text { (quaisquer deles); } \\
\text { [3] O plano comenta, mesmo que em poucos } \\
\text { parágrafos, sobre três dos itens ao lado } \\
\text { (quaisquer deles); } \\
\text { [4] O plano não apenas comenta todos os três } \\
\text { itens ao lado: apresenta-os de forma bastante } \\
\text { descritiva e detalhada, quase exaustiva. }\end{array}$ \\
\hline \multicolumn{3}{|c|}{ BLOCO 2 - O Plano Estratégico em si: metodologia e elaboração - PTC } \\
\hline 24 & $\begin{array}{l}\text { Aspectos institucionais do Território: } \\
\text { ( ) constituição do CODETER/Instituição } \\
\text { parceira } \\
\text { ( ) estrutura do CODETER/ Instituição parceira } \\
\text { ( ) experiência anteriores com planejamentos } \\
\text { regionais } \\
\text { Obs.: }\end{array}$ & $\begin{array}{l}\text { [0] O plano sequer comenta nenhum destes } \\
\text { itens; } \\
\text { [1] O plano comenta, mesmo que em poucos } \\
\text { parágrafos, sobre um dos itens ao lado } \\
\text { (qualquer deles); } \\
\text { [2] O plano comenta, mesmo que em poucos } \\
\text { parágrafos, sobre dois dos itens ao lado } \\
\text { (quaisquer deles); } \\
\text { [3] O plano comenta, mesmo que em poucos } \\
\text { parágrafos, sobre três dos itens ao lado } \\
\text { (quaisquer deles); } \\
\text { [4] O plano não apenas comenta todos os três } \\
\text { itens ao lado: apresenta-os de forma bastante } \\
\text { descritiva e detalhada, quase exaustiva. }\end{array}$ \\
\hline
\end{tabular}

Fonte - Produzido pelos autores (2017).

Quadro 02 - Exemplo de questões que compõe a matriz avaliativa do planejamento dos COREDEs.

\begin{tabular}{|c|c|c|}
\hline \multicolumn{3}{|c|}{$\begin{array}{c}\text { [Especificação do COREDE] } \\
\text { BLOCO } 1 \text { - Elementos do diagnóstico técnico/territorial - COREDEs }\end{array}$} \\
\hline 01 & $\begin{array}{l}\text { Aspectos territoriais do COREDE: } \\
\text { ( ) resgate da formação territorial } \\
\text { ( ) caracterização geral do território } \\
\text { ( ) identificação das transformações recentes na } \\
\text { região }\end{array}$ & $\begin{array}{l}\text { [0] O plano sequer comenta nenhum destes } \\
\text { itens; } \\
\text { [1] O plano comenta, mesmo que em poucos } \\
\text { parágrafos, sobre um dos itens ao lado } \\
\text { (qualquer deles); } \\
\text { [2] O plano comenta, mesmo que em poucos } \\
\text { parágrafos, sobre dois dos itens ao lado } \\
\text { (quaisquer deles); } \\
\text { [3] O plano comenta, mesmo que em poucos } \\
\text { parágrafos, sobre três dos itens ao lado } \\
\text { (quaisquer deles); } \\
\text { [4] O plano não apenas comenta todos os três } \\
\text { itens ao lado: apresenta-os de forma bastante } \\
\text { descritiva e detalhada, quase exaustiva. }\end{array}$ \\
\hline \multicolumn{3}{|c|}{ BLOCO 2 - O Plano Estratégico em si: metodologia e elaboração - COREDEs } \\
\hline 27 & $\begin{array}{l}\text { Aspectos institucionais do COREDE: } \\
\text { ( ) constituição do COREDE } \\
\text { ( ) estrutura do COREDE } \\
\text { ( ) experiência anteriores com planejamentos } \\
\text { regionais } \\
\text { Obs.: }\end{array}$ & $\begin{array}{l}\text { [0] O plano sequer comenta nenhum destes } \\
\text { itens; } \\
\text { [1] O plano comenta, mesmo que em poucos } \\
\text { parágrafos, sobre um dos itens ao lado } \\
\text { (qualquer deles); } \\
\text { [2] O plano comenta, mesmo que em poucos } \\
\text { parágrafos, sobre dois dos itens ao lado } \\
\text { (quaisquer deles); } \\
\text { [3] O plano comenta, mesmo que em poucos } \\
\text { parágrafos, sobre três dos itens ao lado }\end{array}$ \\
\hline
\end{tabular}




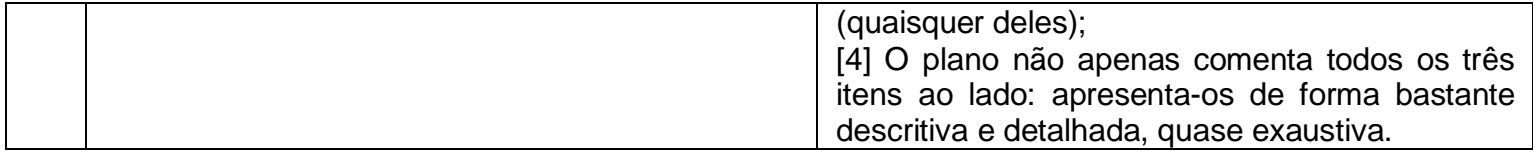

Fonte - Produzido pelos autores (2017).

As matrizes avaliativas foram aplicadas aos quatro TC e aos onze COREDEs analisados. A matriz dos Territórios é composta por 36 questões, conforme as exemplificadas, e dos COREDEs por 39. As questões foram divididas em dois blocos. O primeiro, como anunciado anteriormente, buscou fazer paralelo entre as indicações metodológicas para construção dos diagnósticos e a sua real execução. O bloco dois tratou de averiguar se as demais etapas foram construídas conforme as metodologias adotadas, além de identificar quem construiu o plano e a qualidade da exposição e detalhamento dos projetos propostos.

A aplicação das matrizes ocorreu pelos pesquisadores em três rodadas intervaladas de pelo menos 15 dias a fim de suprimir a possibilidade de interpretações errôneas por motivos diversos. Os resultados obtidos e analisados são compostos da resposta marcada ao menos duas vezes, sendo que em apenas quatro questões nos 15 planos analisados - quatro dos TC e onze dos COREDEs houve três respostas distintas ao fim das três rodadas, sendo atribuída a opção média.

A segunda atividade ainda na terceira etapa metodológica buscou perceber quem foram os agentes envolvidos desde o processo de decisão de planejar, passando pelos planejadores até as regiões/territórios alvo. Para a implementação destas atividades, foi realizado levantamento bibliográfico e documental, além de utilização de entrevistas com os agentes envolvidos nas políticas descritas, buscando auferir elementos não documentados, e identificar particularidades de cada política que venham a contribuir para os resultados da pesquisa.

Com base nas três primeiras etapas da pesquisa ocorreu a quarta, que consistiu na revisão dos documentos que apresentam os resultados dos planejamentos regionais do Rio Grande do Sul e do Programa Territórios da Cidadania - documentos das regiões selecionadas para a pesquisa possibilitando a percepção das peculiaridades nas ações propostas e os elementos regionais percebidos nas primeiras etapas da pesquisa. Para realização desse momento houve duas atividades: a) tratamento das informações trazidas nos planos territoriais, sobre o qual foram traçados questionamentos com base nas peculiaridades levantadas nas etapas anteriores, a partir dessas e com base na Escala Likert, se evidenciou a aproximação do proposto com as realidades regionais, e traçado um perfil qualitativo a partir dos resultados quantitativos da análise - com as perguntas do Bloco 2 exemplificadas nos quadros 01 e $02 . ;$ b) posteriormente, para fins de resultados e discussões finais se apresentou uma classificação das regiões analisadas segundo a aderência das peculiaridades regionais às políticas analisadas.

\section{SÍNTESE DOS RESULTADOS}

São apresentados aqui alguns dos principais resultados encontrados no processo de investigação, divididos em três grupos: a) o primeiro sobre o processo de planejamento, verificando se foram seguidas as etapas propostas nas metodologias divididas em: diagnóstico e processos de participação social; b) vínculo dos projetos propostos com as etapas do planejamento, com a intenção de buscar a fundamentação da proposição de cada projeto, seja por meio do diagnóstico, da participação social ou ambos; e c) a investigação sobre os projetos serem de atenção as peculiaridades regionais ou demandas básicas gerais.

\section{O processo de planejamento}

O gráfico 01 demonstra a síntese comparativa entre os Territórios da Cidadania analisados que construíram seus planejamentos a partir da aplicação da matriz avaliativa com um total de trinta e seis questões respondidas com resultados obtidos a partir Escala Likert. $\mathrm{O}$ eixo $\mathrm{X}$ representa a soma que cada Território atingiu no 'bloco um' de questionamentos sobre o diagnóstico técnico proposto em Brasil (2005), e o eixo Y a soma no 'bloco dois', sobre elaboração e participação social. As linhas demarcatórias demonstram a média para cada bloco.

Caminhos de Geografia $\quad$ Uberlândia-MG $\quad$ v. 21, n. 76 $\quad$ Ago/2020 $\quad$ p. 161-179 Página 169


Gráfico 01 - Síntese dos resultados da aplicação da matriz de avaliação do planejamento do PTC.

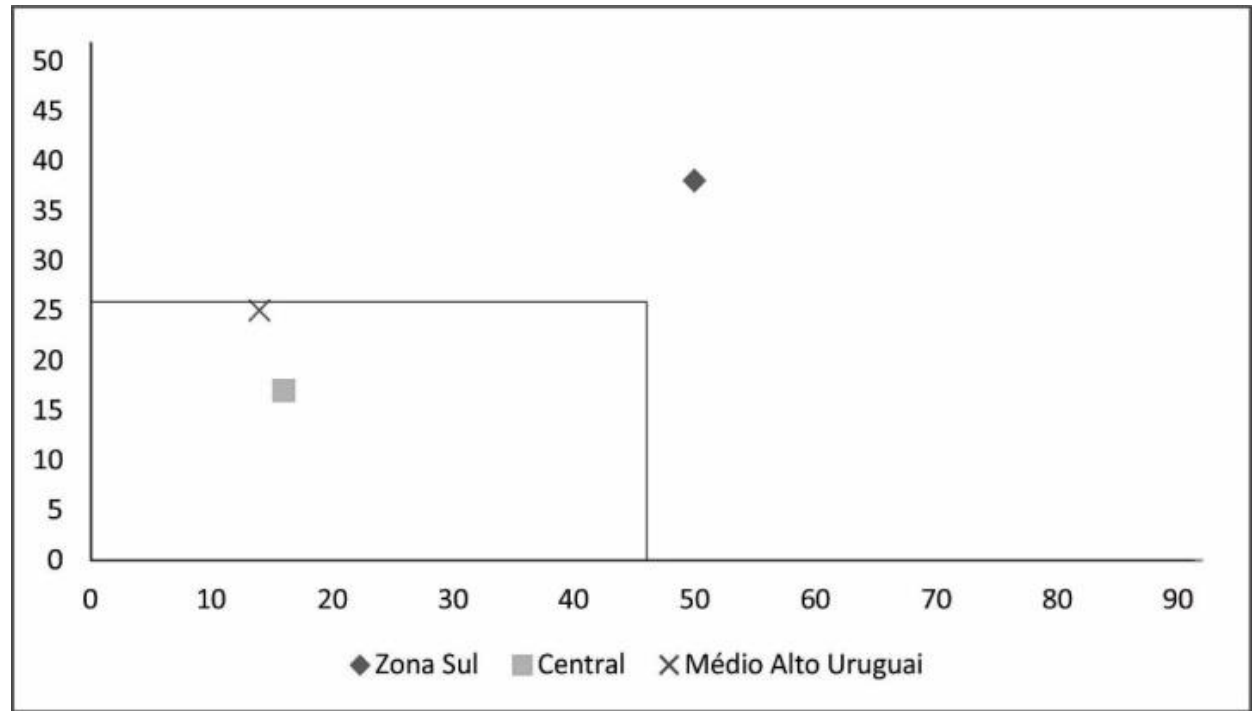

Fonte - Produzido pelos autores (2017).

A síntese das matrizes avaliativas demonstra uma acuidade maior dos agentes planejadores dos Territórios da Cidadania quanto às etapas posteriores ao diagnóstico. $\mathrm{O}$ grau atingido em variados dados assumidos pela metodologia para a construção dos diagnósticos foi baixo, sendo suplantados ou então meramente citados sem maior avaliação crítica, tampouco correlação entre os mesmo e direcionamento das análises para a prerrogativa da própria política.

Não obstante, o mesmo fato que é percebido na análise dos planos dos COREDEs - gráfico 02 ocorre no PTC. A metodologia Brasil (2005) definiu uma gama de indicadores a serem pesquisados para compor o diagnóstico, porém, não há ocorrência de uma reflexão crítica sobre a pertinência de todas as informações como essenciais para a realidade do Território. De modo geral, buscou-se agregar o máximo de dados sem o acompanhamento de uma análise situacional dos mesmos.

Gráfico 02 - Síntese dos resultados da aplicação da matriz de avaliação do planejamento dos COREDEs.

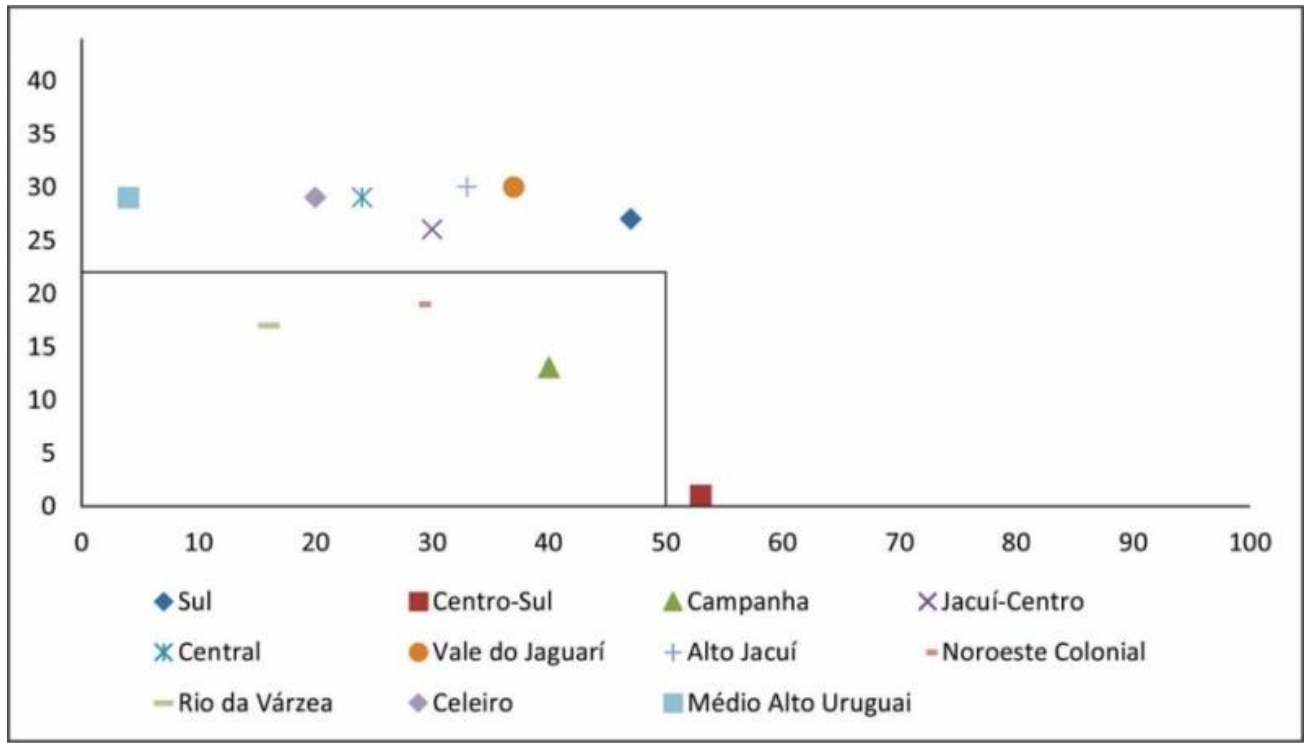

Fonte - Produzido pelos autores (2017). 
No gráfico 02, nos mesmos moldes da análise do PTC, foi demonstrada a síntese comparativa entre os COREDEs da aplicação da matriz avaliativa do diagnóstico e elaboração e participação. Os resultados explícitos na síntese demonstram que a maior fragilidade do processo de planejamento esteve na construção dos diagnósticos para fundamentação das demais etapas.

Relativizar esses resultados é necessário, porém, as proposições dos projetos estruturantes para a região devem remeter ao diagnóstico e ao processo participativo, havendo, assim, uma fundamentação baseada em informações técnicas e empíricas. Em referência nas demais etapas do processo de planejamento nota-se que sete COREDEs obtiveram soma superior à média, mesmo o Médio Alto Uruguai que desconsiderou a construção do diagnostico realizou as demais etapas.

Sobre o processo de planejamento, observou-se uma acuidade maior dos agentes planejadores do PTC quanto às etapas posteriores ao diagnóstico. O grau atingido em variados dados assumidos pela metodologia para a construção dos diagnósticos foi baixo, sendo suplantados ou então meramente citados sem maior avaliação crítica, tampouco correlação entre os mesmo e direcionamento das análises para a prerrogativa da própria política. No caso dos COREDEs, os resultados demonstram que a maior fragilidade do processo de planejamento esteve na construção dos diagnósticos para fundamentação das demais etapas.

Diante da avaliação dos dois blocos de informações propostos nas metodologias para os planos dos COREDEs e PTC - diagnóstico e etapas de participação social -, algumas considerações podem ser apresentadas. É notória a heterogeneidade entre os planos de ambas as políticas, fato que configura para a próxima etapa, a necessidade de maior acuidade quanto ao grau de detalhamento e compreensão das etapas realizadas, pois, ademais as questões do próprio território, as nuanças do processo de construção do plano e mesmo institucionais pesam nos resultados propostos.

Silveira (2014) na análise sobre os planejamentos dos COREDEs relata as distintas interpretações realizadas em cada região das etapas a serem seguidas, fato que culmina na distinção entre os resultados. Nesse interim, foi notório que o maior cumprimento da metodologia esteve no Território com maior enraizamento de atividades anteriores ao processo de planejamento, no caso, o Zona Sul, que já atuava anteriormente ao PTC. No caso dos COREDEs essa resposta fora percebida entre os Conselhos que obtiveram apoio em Universidades Regionais e realizados por equipes multidisciplinares, diminuindo as lacunas existentes na proposta entorno da capacidade técnica das regiões em realizarem os estudos.

Não obstante, o caráter inovador de ambas as políticas quando propõe uma abordagem de corte territorial como base e fim para a construção de suas prerrogativas estratégicas para o desenvolvimento, como abortado em seção anterior deste artigo, corroboram com o atingimento de resultados distantes do ideal. Este fato não decorre necessariamente em função de despreparo e/ou desinteresse das equipes planejadoras, mas sim do pouco acumulo na realização de exercícios como este, fato que reitera a pertinência da continuidade das ações.

Não obstante, o peso maior da participação social em determinadas regiões é fruto também do processo de formação das regiões do Rio Grande do Sul. Como sinteticamente discutido, espera-se que o condicionante - salienta-se o caráter condicionante, não determinante - histórico com base na formação de uma sociedade mais igualitária com acesso a bens sociais esteja em contraste com regiões com histórico escravista, em sociedades hierarquizadas, fatos estes que, mesmo que em partes, verificou-se nesses resultados.

\section{Fundamentação dos projetos propostos}

No prosseguimento da análise dos planejamentos regionais realizados na PTC e pelos COREDEs, volta-se a atenção aos projetos propostos nos planos. O objetivo neste momento é baseado em duas frentes.

A primeira é verificar se há vinculação dos projetos propostos com as etapas anteriores, seja o diagnóstico ou nas etapas com prerrogativas participativas, para averiguar se há "fundamentação" técnica e/ou de base na participação que justifique a inclusão de tal proposta. No segundo momento, buscou-se perceber se cada projeto elencado possui de fato uma preocupação em valorização de condições peculiares à região em questão, juntamente essa é uma das premissas base de ambas as políticas e atenção especial dessa pesquisa. 
Para a realização dessas etapas, primeiramente, foram listados todos os projetos - 359 no PTC e 375 nos COREDEs - trazidos por cada um dos planejamentos analisados de acordo com a sistematização oriunda de cada estudo aliada a metodologia indicada (SIEDENBERG, 2009; BRASIL, 2005).

Posteriormente, foram buscados tanto nos próprios planeamentos como na análise realizada para 0 tópico anterior as vinculações entre o diagnóstico e demais etapas com os projetos elencados.

Assim, a primeira variável apresentada trata da vinculação dos projetos com os diagnósticos realizados. Foram classificados todos os projetos em três categorias: com vinculação direta, indireta e sem ligação. Assim, o gráfico 03 mostra a classificação dos projetos em cada uma das regiões do PTC.

Gráfico 03 - Vinculação dos projetos propostos dos Territórios da Cidadania com o diagnóstico.

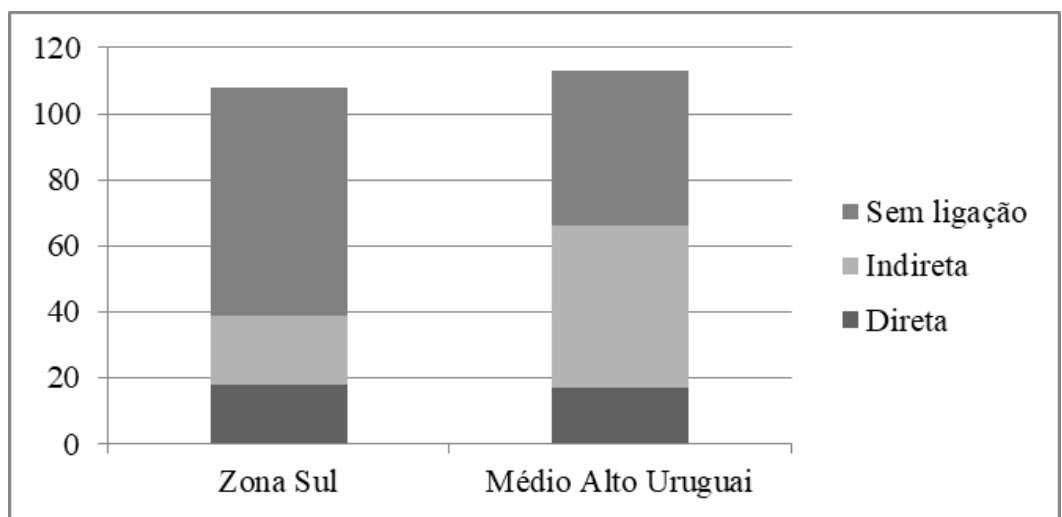

Fonte - Produzido pelos autores (2017)

Nos territórios analisados é perceptível um elevado número de projetos elencados em cada planejamento, em média 120, e o percentual elevado de projetos sem qualquer ligação com o diagnóstico realizado.

Não há presença das informações do Território Central, pois como apresentado no tópico anterior, as mesmas não estão presentes no planejamento, impossibilitando sua análise. Dos dois Territórios analisados percebe-se uma discordância de resultados, com maior fundamentação nas etapas posteriores ao diagnóstico - gráfico 04 - sendo percebidas no Território Médio Alto Uruguai, com aproximadamente $58 \%$ dos projetos fundamentados nessas etapas, enquanto no Zona Sul são apenas $36 \%$.

Gráfico 04 - Vinculação dos projetos propostos do PTC com as etapas posteriores ao diagnóstico.

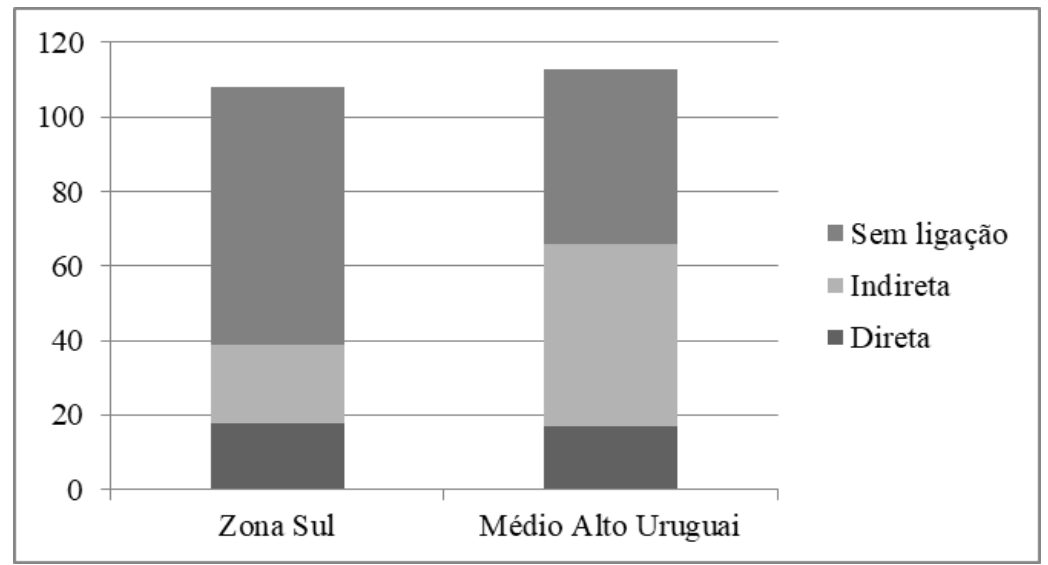

Fonte - Produzido pelos autores. 
Entretanto, diferentemente do verificado na aproximação da análise qualitativa do diagnóstico com os projetos, na análise das etapas posteriores ao diagnóstico, nota-se que apesar do Território Zona Sul ter realizado com maior acuidade tais etapas, a fundamentação dos projetos manteve-se distante. Em paralelo, no Médio Alto Uruguai, com obtenção de resultados inferiores, a fundamentação ocorrera majoritariamente baseada nessas etapas.

Gráfico 05 - Vinculação dos projetos propostos dos COREDEs com o diagnóstico.

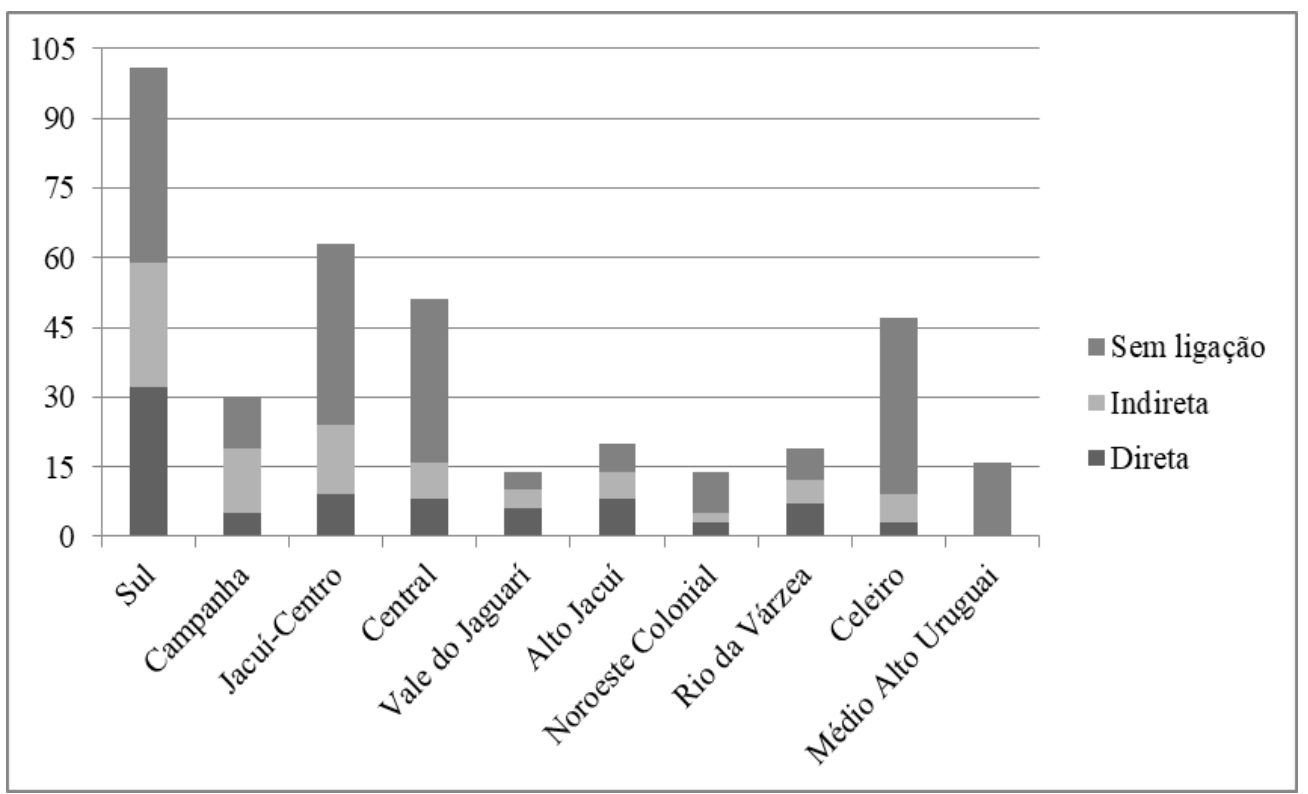

Fonte - Produzido pelos autores (2017)

O gráfico 05 apresenta a mesma relação realizada para o PTC, porém, em referência aos projetos elencados pelos planejamentos dos COREDEs. Entre as onze regiões analisadas, foi subtraído o COREDE Centro-Sul, pois como visto no tópico anterior, o mesmo realizou apenas a etapa do diagnóstico.

Como demonstrado no tópico anterior, os diagnósticos além de no geral apresentarem qualitativamente análises distintas, suprimem diversas informações atribuídas na metodologia. Esses fatos acabam por repercutirem no embasamento dos projetos no diagnóstico, uma vez que, na média, mais de $50 \%$ dos projetos atribuídos não possui qualquer vinculação com esta etapa do processo de planejamento.

Ao aproximar os resultados obtidos da análise qualitativa dos diagnósticos com seu uso para embasamento dos projetos, é possível perceber relação direta entre os resultados das regiões que buscaram cumprir a metodologia de forma mais minuciosa, como o COREDE Sul, e o número de projetos embasados direta ou indiretamente no diagnóstico. Porém, frente ao grande número de projetos propostos, 101 , parte significativa, $42 \%$, não tem embasamento no diagnóstico.

Há, portanto, um alinhamento das demandas atribuídas em forma de projetos em algumas regiões de maneira mais estreita com as informações coletadas e atribuídas com relevância pelos agentes planejadores, afastando-se da prerrogativa metodológica, assumindo resultados distintos das regiões que buscaram abranger o maior número de informações possíveis e traduzi-las em projetos.

Gráfico 06 - Vinculação dos projetos propostos dos COREDEs com as etapas posteriores ao diagnóstico. 


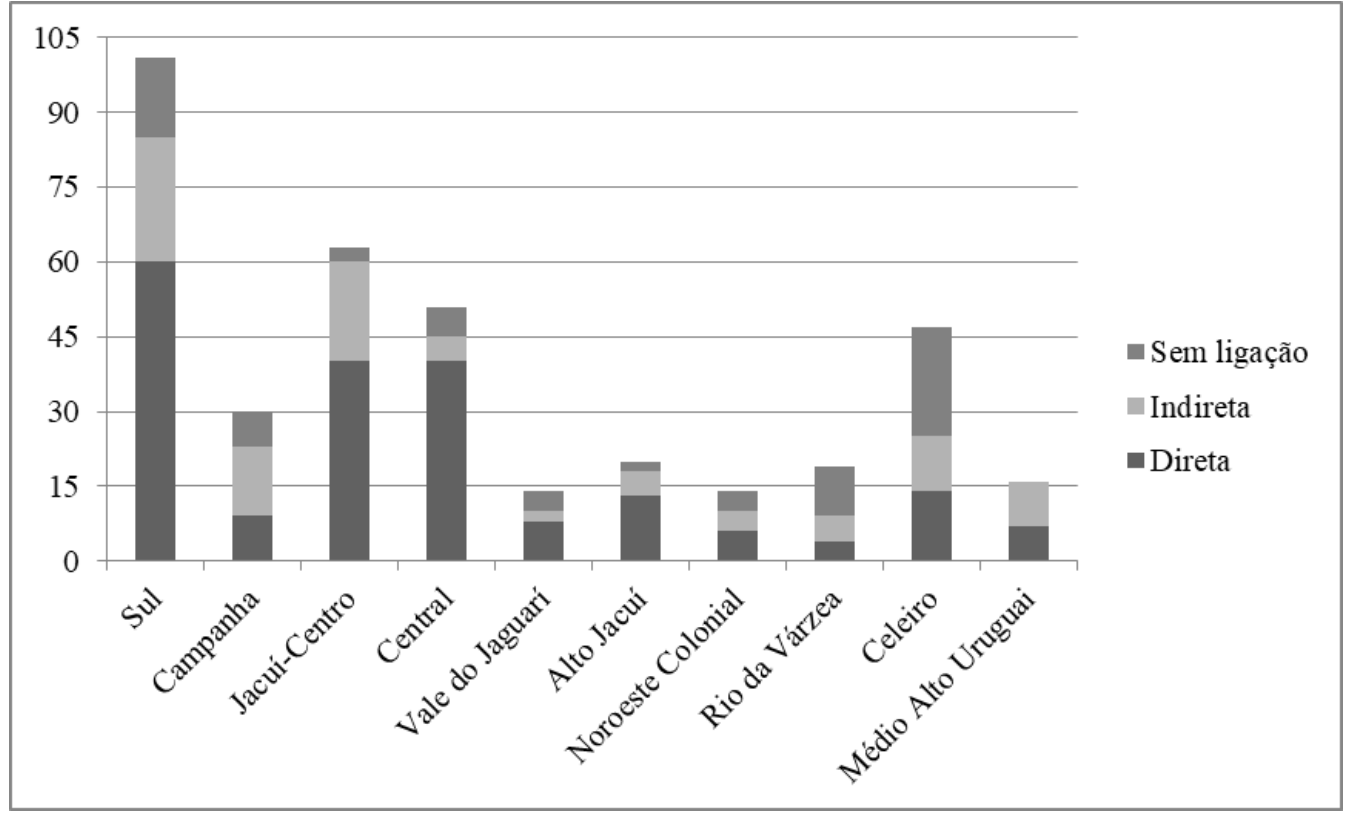

Fonte - Produzido pelos autores (2017).

Nota-se que há uma relação entre os COREDEs que não apenas realizaram todas as etapas, mas sobretudo, as realizaram com graus de participação e reflexão maiores com a utilização desses resultados para proposição de projetos, conforme aponta o gráfico 06.

As prerrogativas que nos são caras para as próximas reflexões apontam para uma existente relação entre a qualificação dos planejamentos com as referidas fundamentações das demandas elencadas. Em concomitância, os Conselhos e Territórios com maior detalhamento de processos e resgate de informações e dados aproximaram-se mais da totalidade de seus projetos com a devida fundamentação, seja no diagnóstico, demais etapas ou em ambos.

Não obstante, se sobressaíram como elemento para fundamentação as etapas em que a participação social fora mais presente em paralelo a vinculação com o diagnóstico técnico. Haja vista as prerrogativas de construção das políticas de modo participativo, o resultado apontar o embasamento das propostas nas etapas participativas é esperado. Não obstante, ao possibilitar voz ao conjunto social, deve-se questionar se os mesmos irão demandar elementos de ordem básica, ou seja, historicamente não atendidas em suas regiões ou irão buscar o desenvolvimento por meio da potencialização de algum elemento peculiar da sua diversidade. Indaga-se isto na próxima seção.

\section{Perfil dos projetos propostos}

A última constatação buscada nos projetos dos planejamentos do PTC e dos COREDEs fora referente ao diálogo entre as peculiaridades regionais e as proposições. Para esse exercício, ao revisar os documentos foram classificados os projetos em duas categorias. Primeiramente, os com relação com peculiaridades regionais ${ }^{1}$, sejam elas de ordem natural, produtiva ou de configuração institucional.

Posteriormente foi tratado de vincular a fundamentação da proposta, seja no diagnóstico técnico, na participação social ou em ambos.

\footnotetext{
${ }^{1}$ A título de exemplificação, o Território da Cidadania Zona Sul propõe o projeto "instalação de parques eólicos em Santa Vitória do Palmar, Rio Grande e Jaguarão", que, em acordo com as características do ambiente e demais especificações técnicas, garante à região uma peculiaridade possível de aproveitamento para a produção de energia eólica. Em paralelo, uma série de projetos elencados pelos COREDEs e pelos Territórios busca dar conta de demandas básicas para o desenvolvimento e não necessariamente é uma carência exclusiva de uma região, mas do conjunto de problemáticas que formam a questão regional do Brasil. Por exemplo, o COREDE Campanha propõe a "melhoria das vias urbanas e rurais", aspecto corriqueiro nas regiões interioranas do país.
}

$\begin{array}{lllll}\text { Caminhos de Geografia } \quad \text { Uberlândia-MG } & \text { v. 21, n. 76 } & \text { Ago/2020 } & \text { p. 161-179 Página } 174\end{array}$ 
Tabela 01 - Número e percentual de projetos de acordo com a aderência as peculiaridades regionais -PTC.

\begin{tabular}{ccc|cc} 
& \multicolumn{2}{c|}{ Básica } & \multicolumn{2}{c}{ Peculiaridade } \\
& $\mathrm{n}^{\circ}$ & $\%$ & $\mathrm{n}^{\circ}$ & $\%$ \\
\cline { 2 - 5 } & 68 & $62,96 \%$ & 40 & $37,04 \%$ \\
Zona Sul & 107 & $77,54 \%$ & 31 & $22,46 \%$ \\
Central & 52 & $46,02 \%$ & 61 & $53,98 \%$ \\
Médio Alto Uruguai & $\mathbf{2 2 7}$ & $\mathbf{6 3 , 2 3} \%$ & $\mathbf{1 3 2}$ & $\mathbf{3 6 , 7 7 \%}$
\end{tabular}

Fonte - Produzido pelos autores (2017).

A tabela 01 demonstra o número e percentual de projetos qualificados como básico e com vínculos com as peculiaridades dos três Territórios da Cidadania analisados. Mesmo com a diversidade territorial do Rio Grande do Sul, percentualmente houve um número não tão significante de propostas que aderiram a peculiaridades regionais, mesmo essa sendo uma das premissas da política em questão.

O resultado de aproximadamente $37 \%$ das propostas com acuidade às peculiaridades é expressivo, porém diante das condições estruturais do território gaúcho e das prerrogativas da política, é questionável os resultados não serem de maior envergadura. A tabela a seguir auxilia nessa compreensão.

Tabela 02 - Percentual de projetos de acordo com a aderência as peculiaridades regionais e básicos e percentual de projetos com vinculação direta e indireta ao diagnóstico e as demais etapas - PTC.

\begin{tabular}{ccccc} 
& Básica & Peculiaridade & Diagnóstico & Demais etapas ${ }^{2}$ \\
\cline { 2 - 5 } Zona Sul & $62,96 \%$ & $37,04 \%$ & $52,78 \%$ & $36,11 \%$ \\
Central & $77,54 \%$ & $22,46 \%$ & $18,12 \%$ & \\
Médio Alto Uruguai & $46,02 \%$ & $53,98 \%$ & $21,24 \%$ & $58,41 \%$ \\
\hline
\end{tabular}

Fonte - Produzido pelos autores (2017).

Somando na análise do percentual de projetos com vinculação às peculiaridades e os básicos com o percentual de projetos fundamentados direta ou indiretamente no diagnóstico e nas demais etapas tabela 02 -, pode-se notar que no Território Zona Sul, com maior fundamentação dos projetos no diagnóstico, há presença maior de propostas de cunho básico, enquanto no Médio Alto Uruguai, com projetos oriundos das demais etapas, cresce o percentual de propostas em diálogo com as peculiaridades. Da mesma forma, o Território Central, que não apresenta as etapas posteriores ao diagnóstico, mais de três quartos dos projetos visam atender demandas básicas.

Tabela 03 - Número e percentual de projetos de acordo com a aderência as peculiaridades regionais COREDES.

\begin{tabular}{|c|c|c|c|c|}
\hline & \multicolumn{2}{|c|}{ Básica } & \multicolumn{2}{|c|}{ Peculiaridade } \\
\hline & $\mathrm{n}^{\circ}$ & $\%$ & $\mathrm{n}^{\circ}$ & $\%$ \\
\hline Sul & 57 & $56,44 \%$ & 44 & $43,56 \%$ \\
\hline Campanha & 18 & $60,00 \%$ & 12 & $40,00 \%$ \\
\hline Jacuí-Centro & 33 & $52,38 \%$ & 30 & $47,62 \%$ \\
\hline Central & 28 & $54,90 \%$ & 23 & $45,10 \%$ \\
\hline Vale do Jaguarí & 6 & $42,86 \%$ & 8 & $57,14 \%$ \\
\hline Alto Jacuí & 10 & $50,00 \%$ & 10 & $50,00 \%$ \\
\hline
\end{tabular}

\footnotetext{
2 A soma das colunas de fundamentação das propostas no 'diagnóstico' ou nas 'demais etapas' não é $100 \%$ devido a falta de fundamentação de algumas propostas ou mesmo a fundamentação em ambos os momentos da pesquisa. 


\begin{tabular}{|ccc|cc|}
\hline Noroeste Colonial & 5 & $35,71 \%$ & 9 & $64,29 \%$ \\
\hline Rio da Várzea & 10 & $52,63 \%$ & 9 & $47,37 \%$ \\
\hline Celeiro & 26 & $55,32 \%$ & 21 & $44,68 \%$ \\
\hline Médio Alto Uruguai & 7 & $43,75 \%$ & 9 & $56,25 \%$ \\
Total & $\mathbf{2 0 0}$ & $\mathbf{5 3 , 3 3 \%}$ & $\mathbf{1 7 5}$ & $\mathbf{4 6 , 6 7 \%}$ \\
\hline
\end{tabular}

Fonte - Produzido pelos autores (2017).

A tabela 03 apresenta o número e o percentual de projetos classificados como básicos e vinculados a peculiaridades regionais em cada COREDE. A visão geral mostra um percentual de projetos vinculados em cada uma das categorias aproximado, com aproximadamente $53 \%$ sendo de demandas básicas e $47 \%$ que aderem peculiaridades.

Essa tabela demonstra que há, de fato, uma atenção na execução da política em considerar as heterogeneidades regionais nas proposições, visto que quase metade das propostas tem essa vinculação. Não obstante, os resultados revelam haver uma tendência também expressiva de busca por atender às demandas básicas da função estatal, como as das áreas de segurança pública, saúde e educação. Obviamente, essas possuem papel central em dinâmicas de desenvolvimento, porém é questionável a sua presença expressiva em políticas que buscam promover o desenvolvimento regional de forma estratégica.

Tabela 04 - Percentual de projetos de acordo com a aderência às peculiaridades regionais e básicos e percentual de projetos com vinculação direta e indireta ao diagnóstico e as demais etapas - COREDEs.

\begin{tabular}{lrrrr} 
& \multicolumn{1}{c}{ Básico } & Peculiaridade & Diagnóstico & Demais etapas \\
\cline { 2 - 5 } Sul & $56,44 \%$ & $43,56 \%$ & $58,42 \%$ & $84,16 \%$ \\
Campanha & $60,00 \%$ & $40,00 \%$ & $63,33 \%$ & $76,67 \%$ \\
Jacuí-Centro & $52,38 \%$ & $47,62 \%$ & $38,10 \%$ & $95,24 \%$ \\
Central & $54,90 \%$ & $45,10 \%$ & $31,37 \%$ & $88,24 \%$ \\
Vale do Jaguarí & $42,86 \%$ & $57,14 \%$ & $71,43 \%$ & $71,43 \%$ \\
Alto Jacuí & $50,00 \%$ & $50,00 \%$ & $70,00 \%$ & $90,00 \%$ \\
Noroeste Colonial & $35,71 \%$ & $64,29 \%$ & $35,71 \%$ & $71,43 \%$ \\
Rio da Várzea & $52,63 \%$ & $47,37 \%$ & $63,16 \%$ & $47,37 \%$ \\
Celeiro & $55,32 \%$ & $44,68 \%$ & $19,15 \%$ & $53,19 \%$ \\
Médio Alto Uruguai & $43,75 \%$ & $56,25 \%$ & $0,00 \%$ & $100,00 \%$
\end{tabular}

Fonte - Produzido pelos autores (2017).

Para compreender as razões para maior aderência de peculiaridades nas regiões frente às outras, a tabela 04 traz os percentuais de projetos de acordo com sua natureza e a existência de fundamentação direta ou indireta com o diagnóstico e/ou as demais etapas do planejamento. A interpretação atingida refere os COREDEs com maior percentual de projetos atentos as peculiaridades, Noroeste Colonial, Vale do Jaguarí, Médio Alto Uruguai, Alto Jacuí e Jacuí-Centro, todos possuem um elevado percentual de projetos fundamentados nas etapas posteriores ao diagnóstico, as essencialmente realizadas a partir da participação social. O diagnóstico técnico não se apresenta como determinante para esse fato, corroborando com a reflexão trazida ao avaliar o estudo técnico ter sido meramente construído como uma etapa do processo, sem a devida acuidade e vinculação possível com os projetos elencados, sejam eles básicos ou peculiares.

Dentre as cinco regiões supracitadas, é passível de menção que em quatro dessas houve participação de universidade regionais na elaboração dos planejamentos: UNIJUI no Noroeste Colonial, UNICRUZ no Alto Jacuí, URI Santiago no Vale do Jaguarí e ULBRA Cachoeira do Sul no Jacuí-Centro; mais do que isso, com composições multidisciplinares nos corpos técnicos.

Por fim, cabe destacar a centralidade da participação social como elemento de fundamentação para os projetos atentos a peculiaridade regional em paralelo aos diagnósticos para basear as propostas 
de ordem básica. Como debatido, o abismo de desigualdades regionais oriundas da formação social e econômica do Brasil e do Rio Grande do Sul deixou um passivo não atendido que vão desde infraestrutura básica até elementos educacionais e de saúde, todos impreteríveis para a constituição de um desenvolvimento atento ao conjunto social. Esta verificação pode - e no caso analisado foi ser percebida em diagnósticos técnicos confeccionados por tecnocratas.

No entanto, a potencialidade de ambas as políticas analisadas está justamente no foco junto as peculiares regionais como vetor para o desenvolvimento e, como demonstrado, é por intermédio da ampliação e qualificação da participação social que é alcançado esse objetivo. As nuanças entre os resultados das regiões perpassam desde elementos oriundos da própria construção dos planejamentos, pelo histórico de acumulo das instituições envolvidas na elaboração e chegam, especialmente, no conjunto social e sua capacidade de impor suas demandas, fato que dialoga eminentemente com o processo de formação de cada umas das regiões.

\section{CONSIDERAÇÕES FINAIS}

Nesta pesquisa foi buscado analisar o tratamento das peculiaridades regionais do Rio Grande do Sul nos Planejamentos Estratégicos Regionais (2009/2010) realizados pelos COREDEs e no Programa Territórios da Cidadania, evidenciando, sobretudo, os elementos determinantes de maior ou menor aderência às especificidades regionais. Assumido como base as repercussões regionais das transformações políticas e econômicas no Brasil e no Rio Grande do Sul em paralelo a conceitos orientadores, foi traçada uma reflexão sobre a formação das disparidades regionais no Brasil e no Rio Grande do Sul sob um olhar de distintas escalas, baseado na diversidade do país.

Através da reflexão do processo histórico da formação da questão regional no Brasil e do Rio Grande do Sul, foi possível traçar um dos aspectos fundamentais para compreender a aderência das peculiaridades regionais nas políticas analisadas. Na formação socioeconômica do Brasil, baseado na rica diversidade natural e sociocultural, um lastro socioeconômico e de infraestrutura fora criado entre as distintas regiões em que as menos favorecidas carecem de uma gama de benefícios sociais, fato que pudera ser percebido posteriormente na análise das políticas analisadas.

Teoricamente, as regiões são definidas na semelhança com seu interior e nas diferenças com seu exterior, porém essas não necessariamente de ordem econômica e social. Ao contrário, busca-se valorizar as diferenças entre essas de ordem produtiva, cultural, para justamente limitar as desigualdades fruto do sistema econômico vigente, ao passo que as políticas de combate às desigualdades regionais, sejam implícitas ou explícitas cumprem fundamental papel, especialmente para as regiões e estratos sociais historicamente desassistidos.

Propostas como essas encontraram espaço na arena política brasileira em anos recentes e valorizando agentes historicamente marginalizados. Nessas, ficou evidente a necessidade de fortalecimento técnico, visto a fragilidade das questões eminentemente técnicas dos documentos que não se traduziram em projetos para as regiões, ou então fundamentaram apenas demandas históricas.

A pertinência dos aspectos técnicos do planejamento, a análise demonstrou que as regiões, sejam dos COREDEs ou PTC, com maior fundamentação das propostas nos momentos de participação social obtiveram maiores índices de aproximação das peculiaridades nos projetos propostos. Baseado nessa constatação, assim como no estudo do IPEA (2014) que afirmou a ampliação da participação como um dos vetores para diminuição das desigualdades no Brasil em anos recentes, o fortalecimento de políticas que possuem essa prerrogativa mostra-se pertinente não apenas pela possibilidade de resultados socioeconômicos, mas também pelo amadurecimento causado pela inserção de demandas consultiva ou deliberativamente pela população nas políticas no ambiente democrático do país.

No entanto, a descontinuidade de políticas públicas no Brasil é um marco. O caso aqui em tela não é exceção. O recente fim do MDA, em maio de 2016, representa um retrocesso nos poucos passos dados em direção da consolidação de políticas públicas de corte territorial com participação ativa da sociedade em sua formulação. Assim, para além dos exíguos resultados materiais alcançados pelo PTC, o próprio acúmulo político do exercício direto de construção de políticas intersetoriais está comprometido. 
No caso dos COREDEs, apesar da instituição persistir no tempo e o amadurecimento das suas proposições juntamente com o exercício de planejamento serem importantes resultados, o parco resultado na luta contra as desigualdades regionais atrelado a crise fiscal do Rio Grande do Sul tem imposto uma sobreposição das ações de curto prazo sobre as planificadas de modo estratégico. Além disso, reflexões recentes demonstram a continuidade ao longo do tempo de desafios que os COREDEs não logram êxito em superar, como por exemplo, a atuação no varejo político em detrimento de ações planejadas. (OLIVEIRA, MARTINS e OLIVEIRA, 2017).

Como verificado na análise, é confirmada em parte a hipótese inicial dessa pesquisa. De fato, parte significativa das políticas analisadas tendem a permanecerem atentas a demandas básicas e com prevalência de propostas setorizadas em detrimento da abordagem territorial.

A formulação top-down do PTC pesou nesse sentido. Todavia, esse aspecto foi menos saliente nos COREDEs, com gênese nas próprias regiões e continuidade assegurada pela sua articulação com estratos das sociedades regionais e com distintas intensidades com o governo do estado. Não obstante, a participação social traduzida especialmente com a presença de instituições de ensino superior comunitárias na execução das propostas e os indicadores de maior aderência das peculiaridades nos projetos dessas regiões, à medida que os fundamentaram nas contribuições da sociedade, fora determinante para a aderência superior das peculiaridades em determinadas regiões. A ocorrência de demandas básicas nas proposições é fruto, também, do histórico de formação socioeconômica do Brasil e do Rio Grande do Sul, quando regiões interioranas do país foram preteridas diante a construção do projeto em voga a depender do momento histórico.

Diante propostas técnicas e participativas que visam superar os gargalos para o desenvolvimento e potencializá-los a partir das peculiaridades, torna-se, portanto, recorrente a busca por sanar questões de ordem chamadas nessa pesquisa de "básicas", que consistem em nada mais que demandas históricas advindas do processo de formação socioeconômica do Brasil e do Rio Grande do Sul. Entretanto, mesmo com as nuanças de ambas as políticas, quantitativamente e qualitativamente as propostas atingiram, mesmo que em partes, a sua prerrogativa de estarem atentas a diversidade regional, distanciando-se das políticas públicas majoritárias no Brasil.

Esse fato decorreu especialmente da atenção desprendida pelos processos de planejamento as demandas colhidas junto a participação social. Parte significativa dos projetos propostos com atenção às peculiaridades regionais foi fundamentada nas etapas participativas do processo de planificação territorial, ao passo que as regiões que obtiveram maior acuidade com tais etapas propostas nas suas metodologias norteadoras tiveram maior proporção de projetos atentos a diversidade regional.

Diante disso, a concepção utilizada pela pesquisa de "projeto atento as peculiaridades" fora decorrente - entre outros fatores - das políticas em si que partem da valorização de predisposições existentes nas regiões. Ao passo que a não existência dessa poderia ser considerada também como uma peculiaridade, entretanto, não configurar-se-iam os objetivos das políticas, fato esse a ser ponderado em um possível replicar desta metodologia a outras ações.

Não obstante, as demandas denominadas básicas tendem a estarem presentes em todas as regiões interioranas do Brasil, salvo exceções. Qualquer reflexão histórica e teórica que busque as raízes das desigualdades regionais no Brasil, independente do foco do estudo, encontrará uma gama de questões ainda não resolvidas nas regiões distantes dos grandes centros ou mesmo nas periferias das cidades.

Fruto da formação histórica do país também fora a prevalência de construção de mecanismos políticos centralizadores e com baixa participação social, de modo que a transformação de estruturas rígidas em distintas direções - centralizador, setorizado, uniescalar - tende a ser complexa e conquistada com o decorrer do tempo e do acúmulo de experiências.

\section{REFERÊNCIAS}

ARAÚJO, Tânia Bacelar de. Brasil: desafios de uma Política Nacional de Desenvolvimento Regional contemporânea. In. DINIZ, Clélio Campolina (org.). Políticas de Desenvolvimento Regional: desafios e perspectivas à luz das experiências da União Europeia e do Brasil. Brasília: Editora da Universidade, 2007. p. 155-172. 2000 .

Ensaios sobre o desenvolvimento brasileiro: heranças e urgências. Rio de Janeiro: Revan, 
ALONSO, José Antônio Fialho; BANDEIRA, Pedro Silveira; BENETTI, Maria Domingues. Crescimento econômico da Região Sul do Rio Grande do Sul: causas e perspectivas. Porto Alegre: FEE, 1994.

Uma experiência de institucionalização de regiões no Brasil: os COREDEs do Rio Grande do Sul. In: FÓRUM DOS CONSELHOS REGIONAIS DE DESENVOLVIMENTO DO RIO GRANDE DO SUL. PRÓ-RS IV: propostas estratégicas para o desenvolvimento regional do Estado do Rio Grande do Sul. Passo Fundo: Passografic, 2010.

BRASIL - Ministério do Desenvolvimento Agrário - Secretaria de Desenvolvimento Territorial. Plano territorial de desenvolvimento rural sustentável: Guia para o Planejamento - documento de apoio № 02. Brasília: MDA/SDT, 2005.

BROSE, Markus Erwin. As origens da participação e da qualidade democrática no Rio Grande do Sul. In: Revista Katálysis, v.10 n.2, Florianópolis, 2007. p. 228-236. https://doi.org/10.1590/S1414$\underline{49802007000200011}$

Superação das desigualdades regionais: uma interpretação da experiência gaúcha. In: CRUZ, José Luis Vianna da. Brasil, o desafio da diversidade: Experiências de desenvolvimento regional. Rio de Janeiro: Senac, 2005.

CARGNIN, Antônio Paulo. Políticas de desenvolvimento regional no Rio Grande do Sul: vestígios, marcas e repercussões territoriais. Tese (Doutorado em Geografia) - Porto Alegre: UFRGS. 2011.

ECHEVERRI, Rafael. Emergência e evolução do programa de desenvolvimento sustentável dos territórios rurais e nos territórios da cidadania. In. FAVARETO, Arilson. Políticas de desenvolvimento territorial rural no Brasil: avanços e desafios. Brasília: IICA, 2010. (Série Desenvolvimento Rural Sustentável; v.12)

INSTITUTO DE PESQUISAS ECONÔMICAS APLICADAS. Capacidades estatais e democracia: arranjos institucionais de políticas públicas. Brasília: Ipea, 2014.

OLIVEIRA, Victor da Silva; MARTINS, Tiago Costa.; OLIVEIRA, Arlindo Escobar Teixeira. Transformações e continuidades nas ações recentes dos Conselhos Regionais de Desenvolvimento do Rio Grande do Sul. FORMAÇÃO (PRESIDENTE PRUDENTE). , v.1, p.63 - 95, 2017. https://doi.org/10.33081/formacao.v1i24.4507

POCHMANN, Marcio. Desenvolvimento e perspectivas novas para o Brasil. São Paulo: Cortez, 2010.

SCHMIDT, João Pedro. O comunitário em tempos de público não estatal. Revista da Avaliação da Educação Superior. Campinas, vol.15, n.1, p. 9-39, 2010. https://doi.org/10.1590/S1414$\underline{40772010000100002}$

SIEDENBERG, Dieter (org.). Fundamentos e técnicas do planejamento territorial: Orientações para o processo de Planejamento Estratégico Regional dos COREDES-RS. Ijuí: UNIJUÍ, 2009.

SILVEIRA, Rogério Leandro Lima. Relatório de Pesquisa: Planejamento e Desenvolvimento Regional no Rio Grande do Sul: uma análise da experiência recente dos Conselhos Regionais de Desenvolvimento - COREDEs-RS. Santa Cruz do Sul: Observatório do Desenvolvimento Regional/CNPq/FAPERGS. Dezembro, 2014.

TAVARES, Maria da Conceição. Da substituição de importações ao capitalismo financeiro: ensaios sobre economia brasileira. Rio de Janeiro: Zahar, 1977.

VEIGA, José Eli da. Vicissitudes da governança cidadã: os conselhos regionais gaúchos (COREDEs). In: Revista de Desenvolvimento Econômico, ano VIII, n.13, Salvador, 2006.

Recebido em: 22/01/2020

Aceito para publicação em: 21/06/2020 